\section{Testicular self-examination: is it still necessary?}

Sir,

More than $90 \%$ of all patients with testicular cancer (TC) present with scrotal symptoms. Therefore periodic selfexamination has been recommended for early detection of testicular cancer. ${ }^{1}$ Unfortunately, this procedure has turned out to be quite unpopular, and it seems that the doctors themselves have contributed much to this nonappreciation. $^{2}$

In recent years, physicians concerned with TC have successfully placed much emphasis on development of new therapeutic regimens. Today approximately $90 \%$ of all patients can be offered the chance of being cured. ${ }^{3}$ In view of this break-through in cancer treatment, it may be suspected that too many doctors have focussed on therapy and post-therapeutic management only, losing sight of the usefulness and benefits of early detection.

For the time being, the development of more effective therapeutic regimens in order to cure even more than $90 \%$ of all TC patients has markedly lost its pace. Toxicity of new protocols is exceedingly high, the corresponding surplus cure-rate being increased to a minor degree only. 4,5,6 Thus, the most promising way of briding the gap between the final goal of $100 \%$ cure-rate and the results of current management is probably a great effort in pretherapeutic measures to achieve a significant 'stageshifting' in future patients. In the light of an increasing incidence of $\mathrm{TC},{ }^{7}$ influencing the prognosis by pretherapeutic measures might also gain economic aspects.

The most important premise for early detection of cancer is awareness of the disease. Recent analyses of data of our patients with TC showed that unawareness prevails. In 190 patients with TC, the mean diagnostic delay before treatment was 170 days. In only ten cases was delay caused by the doctor. Three months after onset of scrotal symptoms, $40 \%$ of all patients still had no medical advice. Moreover, there were 21 of 202 patients presenting with extratesticular symptoms only, in 13 of

\section{References}

1. Garnick, M.B., Mayer, R.J. \& Richie, J.P. Testicular self-examination. $N$ Engl J Med 1980, 302: 297.

2. Goldbloom, R.B. Self-examination by adolescents. Pediatrics 1985, 76: 126-128.

3. Oliver, R.T.D. Testicular germ cell tumours - a model for a new approach to treatment of adult solid tumours. Postgrad Med J 1985, 61: 123-131.

4. Ozols, R.F., Deisseroth, A.B., Javadpour, N., Barlock, A., Messerschmidt, G.C. \& Young, R.C. Treatment of poor prognosis nonseminomatous testicular cancer with 'high dose' platinum combination therapy regimen. Cancer 1983, 51: 1803-1807.

5. Roth, B., Einhorn, L., Williams, S., Loehrer, P. \& Bonnem, E. Alpha-2 interferon in the treatment of refractory malignant germ cell tumors. Proc Am Soc Clin Oncol 1985, 4: 100. whom simple scrotal palpation revealed testicular masses that had no been noticed by the patients themselves. Nine of these patients with advanced cancer died due to drugresistant disease. This example again illustrates the fatal outcome of advanced testicular cancer after long delay. ${ }^{8}$ At the same time, it points out how easily the diagnosis might have been established much earlier if only the patients had been aware of the disease.

Stimulated by these observations, we recently conducted a study in order to verify the public unawareness of TC; 596 healthy young male individuals were asked by a questionnaire about their knowledge of TC and the value of self-examination. Only $5.3 \%$ of all participants answered all the questions correctly, while $70 \%$ replied incorrectly to more than two of the eight questions. It was striking that the most important issues for early detection, and symptoms of TC, proved to be unknown to the majority of the young men. These results are in accordance with those of Thornhill et al..$^{9}$ and Cummings et al.,10 thus giving evidence that unawareness of testicular cancer is not a problem of selected areas only.

In summary, increasing incidence of TC, doubtful perspectives in the development of more effective therapeutic regimens, world-wide evidence for unawareness of TC in the public, and finally the well-known deleterious impact of diagnostic delay should call back our attention to the value of prevention. There is an urgent need for distribution of more specific information in the general public, and strong efforts are to be made for propagation of testicular self-examination.

K.-P. Dieckmann Department of Urology, Steglitz Medical Center, Free University of Berlin, Hindenburgdamm 30, D-1000, Berlin 45, F.R.G.

6. Greco, F.A., Johnson, D.H., Wolff, S.N. et al. A phase II study of high dose VP 16-213 and autologous bone marrow transplantation for refractory germinal neoplasms. Proc Am Soc Clin Oncol 1983, 2: 138.

7. Davies, J.M. Testicular cancer in England and Wales: some epidemiological aspects. Lancet 1981, i: 928-932.

8. Jones, W.G. \& Appleyard, I. Delay in diagnosing testicular tumours. Br Med J 1986, 290: 1550.

9. Thornhill, J.A., Conroy, J.M., Kelly, D.G., Walsh, A., Fennelly, J.F. \& Fitzpatrick, J.M. Public awareness of testicular cancer and the value of selfexamination. $\mathrm{Br} \mathrm{Med} J$ 1986, 293: 480-481.

10. Cummings, K.M., Lampone, D., Mettlin, C. \& Pontes, J.E. What young men know about testicular cancer. Prev Med 1983, 12: 326-330. 